\title{
Performance management and employee engagement: A South African perspective
}

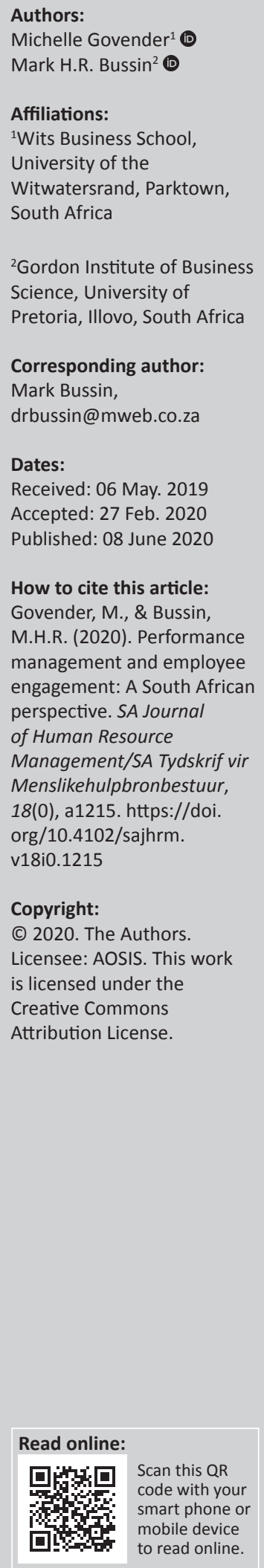

Orientation: To remain competitive South African organisations must improve their operational efficiency by lowering manufacturing and service costs, and the key is the performance of its employees.

Research purpose: The purpose of the study was twofold: firstly, to establish if there is a relationship between performance management and employee engagement; and secondly to ascertain if performance management can be rebooted through increased employee engagement.

Motivation for the study: Organisations that measure and manage performance generally outperform those that do not. Organisations need to understand what drives employee engagement and performance to outperform their competitors.

Research approach, design and method: A qualitative approach was employed that included a review of research articles and interviews with employees from various functions across all levels within operations of a fast-moving consumer goods organisation based in Gauteng. A sample size of 20 employees was used.

Main findings: The results suggest that a relationship exists between performance management and employee engagement and that an increase in employee engagement would result in improved performance of employees and subsequently the organisation. The study revealed that whilst engagement and communication occur across all levels within the organisation, there is still a significant gap. The messages and expectations are not simple enough to be understood. Employees are not empowered to have a voice which causes them to be demotivated. Supportive management, which is fundamental to the success of performance management, is lacking.

Practical/managerial implications: The insight from this study may be used to change the way organisations engage with employees and manage performance to ensure it is a beneficial exercise that adds value to all stakeholders.

Contribution/value-add: This study will contribute towards organisations understanding the relationship between performance management and employee engagement and how to leverage this towards improving operational efficiency and organisational effectiveness.

Keyword: performance management; operational efficiency; organisational effectiveness; employee engagement; South Africa.

\section{Introduction}

Top performing companies are those that are successfully able to translate business and talent strategies into reality faster and more efficiently than their competitors. Hattingh, De Waal and Parsons (2018) acknowledged that there was a shift in the global economy since the financial and economic crisis of 2008. Hill (2013) recognised that cross-border trade and investment barriers are declining and doing business in foreign countries is becoming easier as administrative and regulatory barriers are reduced, allowing both small and big organisations from developed to developing economies to expand internationally. Globalisation, Big Data, the Internet of Things and advances in technology ensure that organisations only have one major differentiation - their employees.

Van der Walt (2018) concluded that sustaining high performance to create a competitive advantage in an increasingly turbulent economic environment is crucial. Performance management is an essential tool used for the effective management of organisations. It is used to assess achievement of agreed key performance indicators, develop talent, build competencies and enhance skills of 
employees, thus ensuring continued success. Aguinis (2013, p. 2) defines performance management 'as a continuous process of identifying, measuring and developing the performance of individuals and teams and aligning performance with the strategic goals of the organisation'. According to Melnyk, Bititci, Platts, Tobias and Andersen (2013), there are studies, however, that show that performance management can adversely impact performance when a misalignment exists between what the organisations want to achieve and what is being measured. The reality is that the key competitive advantage of organisations today is the performance of their employees.

As suggested by Gruman and Saks (2011), employee engagement has been cited as having considerable popularity over the last couple of years and plugged as the key to an organisation's success. It seems that leaders are fast making the connection between engaged employees and business success. 'There is an increasing awareness that employee engagement is pivotal in commercial and business performance' (Robertson-Smith \& Markwick, 2009, p. 2). No longer are engaged employees a nice to have; they are a must to have if an organisation wants to outperform its competitors. Robinson, Perryman and Hayday (2004) define employee engagement as:

$[A]$ positive attitude held by the employee towards the organisation and its value. An engaged employee is aware of business context and works with colleagues to improve performance within the job for the benefit of the organisation. The organisation must work to develop and nurture engagement, which requires a two-way relationship between employer and employee. (p. 8)

The biggest challenge that leaders in organisations face is how to build a culture of employee engagement and leverage this as a driver of performance. How to make employee engagement work to positively change behaviour and improve operational performance is a concern. Bedarkar and Pandita (2014) state that employees want to be engaged in and contribute to the larger organisation.

\section{Research purpose}

Managing performance must be a continuous process to be effective; it must be a part of the way a company does business. For most organisations in South Africa, it is a biannual tick box exercise that leaves managers and employees unchanged either way. De Leeuw and Van Den Berg (2011) stated that organisations that measure and manage performance outperform those that do not do these. Strauss and Du Toit (2010) argued that South Africa lacks competitiveness. How then does South Africa compete and survive in the global arena?

Hoole and Bonnema (2015) stated that a gap exists between the realisation of employee engagement and ideal engagement levels. The supposition is that the level at which an organisation performs will be in part determined by the level of engagement its leaders have with their employees.
Hoole and Bonnema (2015) further suggested that in the current economic situation, a workforce that is engaged may provide the competitive edge required for organisations to succeed, and that whilst low levels of engagement may negatively impact the bottom line, high levels add value. An employee who feels valued and sees himself or herself as an integral part of the organisation is the one that is more likely to contribute towards the success of that organisation.

According to Schaufeli, Salanova, Gonzalez-Roma and Bakker (2002), engaged employees see themselves capable of dealing with demanding jobs and are connected to their work activities. The connection made between employer and employee is what will give an organisation a competitive advantage over another. The value people contribute cannot be imitated or duplicated by competitors. Levels of engagement differ, organisational cultures differ, employees differ in the way they adapt to change, leadership styles are not the same from one organisation to another - all these factors must be considered to make both performance management and employee engagement work. 'A "one size fits all" approach to enabling engagement is ineffective, because levels of engagement and its drivers vary according to the organisation, employee group, the individual and the job itself' (Robertson-Smith \& Markwick, 2009, p. 46).

Although extensive literature exits on both performance and employee engagement, there is paucity of literature on the relationship between the two within the South African context. The purpose of this study was to contribute to existing knowledge regarding the relationship between performance and employee engagement. The insights gained from the study are to contribute to existing literature and help South African organisations understand their employees' views on managing performance and employee engagement, leveraging this knowledge to change the way they engage, and manage their employees to improve performance and grow the business.

\section{Objectives}

To address the paucity of literature that exists on the relationship between performance and employee engagement within the South African context and to understand whether increased employee engagement can improve performance, the following objectives will be explored, namely, to:

1. understand how to effectively engage employees to ensure increased performance

2. ascertain how to leverage employee engagement to reboot performance management.

\section{Literature review Performance management}

\section{What is performance management?}

Aguinis (2013, p. 2) states that 'performance management is a continuous process of identifying, measuring, and developing the performance of individuals and teams and aligning 
performance with the strategic goals of the organization'. It is relevant to note that Aguinis highlights two critical points for organisations; the first point is that it is a 'continuous process', which means ongoing. Organisations conduct bi-annual performance appraisals on their employees confusing it with performance management. This highlights a lack of understanding by managers and human resource business partners. Performance appraisal sessions are usually a tick box exercise for managers, an administrative hurdle imposed by human resources (Smither \& London, 2009). The second point is 'aligning performance with the strategic goals'; business needs change and these changes must translate into changes in employee objectives. If performance appraisals are conducted twice a year, then how are organisations ensuring this alignment?

Performance management is not the same as performance appraisal (Smither \& London, 2009). Aguinis (2013) and Smither and London (2009) are aligned when they conclude that performance management is not the same as performance appraisals. Aguinis (2013) describes evaluations that are done once or twice a year without constant coaching and feedback to employees as performance appraisal, where objectives of the employee's contributions are not clearly set out. Aguinis (2013) and DeNisi and Pritchard (2006) state that performance appraisal forms part of performance management. They also concur that performance management can be defined as various activities that occur throughout the year and are not a shaped or defined set of events. These activities focus on motivating employees to improve their performance.

\section{The importance of performance management}

According to Aguinis (2013), there are several reasons for managing performance that are beneficial to organisations, managers and employees alike; however, for the purposes of this research study, we shall limit the review to those that are most relevant to the study and which were highlighted in participants' responses. They include the following:

1. Employees are encouraged and motivated when they are recognised for good work; it boosts their morale and makes them want to do better.

2. Employees want to be recognised and feel valued; this satisfies a basic human need and motivates them.

3. Managers get to know their employees, which builds better relationships, opens the channels for an honest two-way communication and allows for the manager to understand how to effectively manage the employees for sustained performance.

4. Employees get a greater understanding of their roles in achieving organisational objectives and their managers' expectations, including the behaviours they must display.

5. Employees are encouraged and motivated by constructive feedback; they are encouraged by their managers' interest in them and gain valuable insights into their strengths and want to know how they are performing to work on their areas of development and improve future performance. Employees become more competent.
6. Organisational goals are given clarity, and this helps employees understand the relevance of their role in supporting the achievement of the team and business objectives.

7. Timely and meaningful feedback occurs which allows for employees to be supported in correcting performance to achieve individual and business objectives.

8. Employees are given a voice; they can share their ideas for improvement and raise concerns for timely resolution, which improves organisational performance.

\section{The consequence of a poorly implemented and managed performance management process}

A poorly implemented performance management system can have a significant negative impact on business results. Aguinis (2013) explains that if the performance management system lacks credibility and is seen as unfair, then employees would either leave the organisation or become silent. Feedback that is not constructive leads to employees feeling demotivated, and employees who are not motivated are not productive. Employees who do not trust in the ability of their manager to effectively manage performance will find the employee and manager relationships being destroyed. When performance management is not effectively implemented, it becomes a tick box exercise that adds no value to the employee who is left discouraged and unchanged; the manager has wasted his, the employee's and the organisation's time because there will be no improvement all round. A performance management process that is not consistently applied across the organisation will have ratings and standards that may vary, be unfair and, as a result, employees will be unclear of how the ratings were generated. Bias leads to unhappy and discouraged employees who do not trust the performance management process.

\section{Employee engagement}

\section{What is employee engagement?}

Employee engagement is the level of commitment and involvement an employee has with the organisation. Schaufeli (2013) states that in business engagement is a blend of job satisfaction, being committed to the organisation and extra-role behaviour in that an employee is willing to go beyond what is in his or her job description. An employee that is engaged will go the extra mile without being coaxed, believes in the values and vision of the organisation and wants to contribute to its success. Engaged employees are part of the solution and step up to the plate to deliver business results. Kahn (1990, p. 694) introduced the concept of employee engagement as 'the harnessing of organization members' selves to their work roles; in engagement, people employ and express themselves physically, cognitively, and emotionally during role performances'.

According to Lockwood (2007), there are different levels of engagement which organisations must be cognisant of, which could either positively or negatively impact organisational performance. The first level of engagement includes the 'engaged employee' who is passionate about his 
or her job, feels connected to the organisation and drives superior performance. The second level of engagement is the 'not engaged employee' who is there to earn a living; he or she has no interest or passion for his or her work. The last level of engagement describes the 'actively disengaged employee' who is unhappy and shows it, undermining the achievements of engaged employees. As a leader, being able to recognise the level of engagement an employee has is important in managing the employee.

Employee engagement is regarded as cognitive, emotional or behavioural (Khan, 1990). What an employee believes about the workplace culture, its managers and the organisation is referred to as cognitive engagement. How employees feel about the organisation, management and fellow coworkers is referred to as emotional engagement. The value the employee adds in terms of discretionary effort and energy put into his or her work is the behavioural factor (Lockwood, 2007).

\section{The benefits of employee engagement}

Robertson-Smith and Markwick (2009) maintained that engaged employees perform $20 \%$ better than their co-workers because they immerse themselves fully in their work. Talented, engaged people who are aligned to the business strategy and feel connected to the organisation are more likely to stay with the organisation, thus reducing employee turnover and ensuring business continuity. Employees who are engaged positively influence their fellow workers, thus improving not only individual performance but also team performance. This has a roller-coaster effect on the organisation. High-performing teams hold themselves accountable for performance, which delivers business results. A similar view was shared by Lockwood (2007), who affirmed that business success is determined by the levels of engagement within an organisation. An increase in the levels of employee engagement helps in the retention of talent, increases stakeholder value, improves loyalty of customers and subsequently improves organisational performance.

\section{Drivers of employee engagement}

According to Robertson-Smith and Markwick (2009), a 'onesize-fits-all approach' will not deliver the desired benefits of employee engagement because the levels of engagement and drivers of engagement are not the same. They identified several key drivers of employee engagement, which include the following:

Nature of work: the kind of work an employee has or is expected to do greatly influence how engaged he or she is. Employees want work that is exciting, uses their skills and capabilities, and challenges them. They want to know that the work they do adds value and is important to them and others.

Work that has purpose and meaning: employees want to feel as if they are making a difference; they want to feel proud of their organisation, what it does and their own work.
Opportunities for development and improvement: employees want to develop their skills and growth in their careers. Managers and organisations must encourage employee development through regular feedback discussions. Engaged employees feel empowered and when they are confident in their ability and their job, they perform at their best.

Reward and recognition: employees want to be recognised; they want to feel appreciated and valued. Relationships that are effective: maintaining good and productive relationships with peers and managers is important. It must be a trusted relationship where there is mutual respect and open dialogue. Managers can show trust in employees by allowing greater autonomy. The organisation must support a culture of trust. Two-way communication: employees must be consulted in decision-making and allowed to have a voice.

Inspiring leadership: managers must adopt a collaborative approach; they must act with integrity and inspire employees.

The drivers identified above by Robertson-Smith and Markwick (2009) as being key to performance management are supported by a study conducted in 2006 in Singapore by the Gallup Group, which concluded that the key employee expectations that form the basis of engagement include employees wanting to know what is expected from them and the necessary tools to perform their jobs. They wanted to use their skills and talents and they wanted recognition. It was important that they feel valued. Feedback on how they are performing was important; they want opportunities to learn and they want to have good relationships with their coworkers (Gopal, 2006).

\section{Interpretation of the management theory constructs common to performance and employee engagement}

While all the themes will be discussed, the focus will be on the constructs that emerged as the three major themes of the study, which are engagement and communication, employee empowerment and authentic leadership.

\section{Engagement and communication}

Hoole and Bonnema (2015) argued that engaged employees can enhance the competitiveness of organisations in the current economic landscape and that while high levels of engagement add value, low levels of engagement can have a damaging effect on the bottom line. Robertson-Smith and Markwick (2009) pointed out that various studies have demonstrated a correlation between high employee engagement levels and productivity of employees, teams and organisations. They argued that engaged employees show commitment, advocate on behalf of the organisation, show dedication, use discretionary effort and utilise their skills and abilities to support the achievement of the organisation's goals. They feel a connection with the organisation and invest themselves into their roles and into the organisation. When organisations encourage a culture of enabling employees, they benefit not only financially but also 
have the advantage of employees who are willing to go the extra mile and do whatever it takes for the organisation to succeed (Baumruk, 2006).

Lockwood (2007) argued that continuous communication is a key management tool that gives credibility to the organisation's leadership and ensures organisational success. The same argument was made by Lowry (2016) who stated that critical to business success was the communication of clear, consistent messages to employees. It was further explained that the reasons organisations fail are because leaders assume that important information will be filtered down to the lower levels. According to Lockwood (2007), consistent, clear and honest communication encourages, energises and keeps employees productive. A lack of clear or poor communication can lead to distrust, high turnover, frustration and doubt. It is important for organisations to have a strategic communication plan that encompasses what will be communicated and the methods of communication. Delivery methods must be adapted to the audience. Effective communication is a two-way process. According to Morrison (2014), employees who engage in an upward voice are willing to provide the organisation with valuable information, raise concerns or give input, and when they are demotivated and stop having a voice, they may be depriving the organisation of useful information. It is therefore important that employees are given an opportunity to have a voice without fear of intimidation or victimisation.

Aguinis (2013) states that timely and meaningful feedback allows for employees to be supported in correcting performance to achieve individual and business objectives. Performance discussions and feedback must take place regularly; it must not happen annually or bi-annually. The performance appraisal process is not the same as the performance management process. Organisations, human resource managers and management need to be trained to understand the difference between these constructs. Performance management is a continuous process of twoway discussions and feedback. The absence of regular discussions and feedback results in employees feeling blindsided and disengaged when the annual or bi-annual appraisals happen. Often objectives are not met because throughout the year there was no feedback on performance or support to achieve objectives. This negatively impacts employee performance and organisational performance. A regular two-way communication allows for a culture of transparency and openness, where any form of confusion or doubt can be quickly and amicably resolved, creating an environment of trust. Employees who trust are loyal and will go the extra mile to achieve business results.

Regular and constant communication between employees and management allows for issues or problems to be identified early and resolved quickly. A continuous process of evaluation and mentoring will ensure that employees are skilled and developed to improve their own opportunities for career growth and to ensure business success. When constructive and honest feedback is given to employees, it encourages them to leverage their strengths and work on their areas of development to maximise performance.

\section{Employee empowerment}

Lockwood (2007) argued that:

[W] hen employees have the power to make decisions related to their performance, can access information about company costs and revenues, and have the necessary knowledge, training and development to do their jobs - and are rewarded for their efforts - they are more productive. (p. 3)

According to Anitha (2014), employees are more interested and engaged when they know that their contribution adds value and brings a positive difference to the organisation. Menon (2001) argued that allowing employees to make work-related decisions to enhance performance is not new in management literature and that empowering employees would allow them the ability to significantly affect organisational outcomes. Empowerment is the result of increased participation of employees. All these authors are aligned in their view that empowered employees enhance organisational performance.

Menon (2001) further states that by providing a vision for the future, leaders energise and empower their employees to act by participating in transforming the organisation. Menon argues that the true benefit of empowerment will only be realised if employees experience empowerment; he alludes to the fact that most organisations profess to empower employees by asking leaders to get them involved in the decision-making process, but in the hierarchy of the organisation, it is about control. According to Menon (2001), empowerment initiatives fail because of the inability of leaders who cannot delegate effectively, their need for power and their insecurity with their own jobs.

Aguinis (2013) states that employees are encouraged and motivated when they are recognised for good work, and it boosts their morale. Employees who are motivated get involved and take initiative. Intrinsic motivation which is fuelled by feelings is perceived as more important to employees than monetary rewards. Employees want as recognition for good work and developed competencies the freedom to make decisions and to feel empowered. When employees are given a voice and are allowed to share their ideas for improvement and raise concerns for timely resolution, it improves organisational performance. A key contributor to organisational success in today's everchanging and increasingly competitive business arena is employee engagement. Schaufeli et al. (2002, p. 74) define engagement as 'a positive, fulfilling, work-related state of mind that is characterised by vigor, dedication and absortion'. Engaged employees are productive employees; they want to be empowered, they demand support from their leaders and they want to deliver business results through improved performance. By giving employees a voice, and allowing them to share ideas, make suggestions and raise concerns, it makes them feel included. Increasing the opportunities given 
to employees to contribute or participate in the direction of the company will encourage and motivate them to know that their inputs are valued. Employees who feel valued are productive employees.

\section{Authentic leadership}

George, Sims, Mclean and Mayer (2007) argued that:

[A]uthentic leaders demonstrate a passion for their purpose, practise their values consistently, and lead with their hearts as well as their heads. They establish long-term meaningful relationships and have the self-discipline to get results. They know who they are. (p. 129)

From this definition it can be concluded that a leader's role is to create an environment that encourages employee participation and provide supportive management to employees that motivates them to use discretionary effort, and be a role model - an individual who leads by example consistently applies ethical values and is someone who forms trust relationships.

The success and effectiveness of performance management lies in the quality of the leader and his or her commitment to engage with, provide support to, challenge, coach, give constructive feedback and include his or her employees in activities of the business (Gruman \& Saks, 2011). Sanger (2008) argued that effective performance management requires a change in culture and skilled leaders who are willing and committed to provide considerable managerial investment. The point is further illustrated in the work by Smither and London (2009) where it is cited that:

The second big gap is tied to the skills of performance 'managers'. Short of training them as psychologists, many struggle with the challenges of setting proper goals with their people, providing timely and meaningful feedback in a constructive fashion, and coaching people to bring out the best in them. (p. 81)

Aguinis, Gottfredson and Joo (2012) suggest that often managers do more harm than good when giving performance feedback because they are not comfortable with it and therefor a constructive feedback approach should be used rather than one that relies on employees' shortcomings. Gruman and Saks (2011) argued that leaders motivate and encourage employees to try new things by showing support, giving employees stretch roles and allowing employees to participate in discussions and get involved in decisionmaking without fearing negative consequences.

Authentic leaders inspire and motivate employees to outperform. Performance management must be fair, transparent, objective and used as a tool for improvement and not punishment. The role of supportive management and authentic leaders is critical to the performance management process. If employees lack confidence in their leaders to effectively manage performance, they will become disengaged and demotivated. Leaders need to undergo training on how to manage performance and to increase their emotional intelligence. Managers who are trained and equipped to be supportive of employees and show interest in their development form better relationships with employees. Leaders need to reinforce and keep landing the message with employees that their role within the organisation is key to its success and that their contribution is valued. An employee's interest and engagement are increased when his or her work is regarded as meaningful (Anitha, 2014).

\section{Development and improvement}

Development and improvement is another key construct that must be considered when engaging employees. Anitha (2014) suggested that employees gain confidence when they are trained and developed, which allows them to engage significantly in their jobs. When individuals and teams are engaged, there is a higher level of productivity and so organisations must be quick to leverage this and explore opportunities to develop these individuals and teams into stretch roles. Organisations must ensure that the competencies and development of these employees are understood and acted upon - this will ensure that these individuals remain motivated and encouraged to grow with the business and to grow the business. According to Lockwood (2007), as organisations compete globally, attracting and retaining the right talent will be increasingly more important. Employees wanting greater work-life balance means that organisations must understand employee needs and how to meet them, yet still develop and leverage talent at all levels of the organisation. Another key consideration is that because of the poor education system, employees starting their careers might not have the right level of skills needed and organisations would need to partner with schools and universities to acquire the required skills.

Building capability for the future will be positively related to increased performance. Aguinis (2013) states that employees are encouraged and motivated by constructive feedback; they are encouraged by their manager's interest in them and gain valuable insights into their strengths. They want to know how they are performing to work on their areas of development and improve future performance. It is important for organisations to have effective training programmes in place to increase the skills and competencies of employees. Employees want to be developed; they want to improve their own performance to better support in the achievement of organisational objectives. Organisations need to recognise the changes in work-life balance and develop and retain talent. Employees must have the right skills and competencies and display the right behaviours aligned with the values of the organisation. Performance discussions must include the 'how' in terms of achieving objectives. For sustained performance it is important to have employees act with integrity. If organisations measure behaviour, then there is a greater chance of having authentic leaders at all levels of the organisation, which would increase performance and allow for sustained performance.

\section{Performance management soundness and roles}

Employees' perception of the performance management system is poor and often perceived as the 'big stick' (Bourne, Neely, Platts, \& Mills, 2002). Employees are not part of the 
performance management system - goal setting, objectives are decided by senior management or global teams and cascaded to employees and therefore there is no buy-in of the process from the onset. In order to be accepted, goals should be understood and meaningful. De Leeuw and Van Den Berg (2011) suggested that a lack of motivation and resistance to change may be the result of not involving personnel in performance management systems. There is a lack of employee participation during the performance management reviews, with discussions often being led by the manager. Performance feedback sessions are often not conducted on a regular basis and the performance management reviews do not include development discussions.

\section{Workplace culture}

Lockwood (2007) argued that to effectively engage employees, organisations must first understand the nature of their workplace culture; is it too results focused that employees are left behind, or does it provide employees with a sense of purpose, connecting leaders and employees in their shared beliefs and enabling employees to contribute in the direction of the organisation?

\section{According to (Lockwood (2007):}

Research shows that organizations that provide a workplace culture with the psychological conditions of meaningfulness (job enrichment, work-role fit), safety (supportive manager and coworkers) and availability (resources available) are more likely to have engaged employees. (p. 5)

An organisation that can provide meaningful work, supportive management and adequate resources is more likely to have engaged employees. Organisations must create an environment of trust that could encourage mutual respect and build good relationships. When the culture of the organisation is one of support, engagement, development and continuous improvement, it allows for employees to want to be a part of the organisation; they are proud of it, they will defend it and they want to be part of its success. They use discretionary effort to ensure that the organisation succeeds. The organisation must ensure that there is an effective engagement policy in place to ensure employee engagement levels are measured and improved continuously for sustained performance.

\section{Rewards, recognition and appreciation}

Saks and Rotman (2006) concluded that employees will positively involve and engage themselves more in their roles should they perceive that the rewards will be greater, and should they be given recognition that their work is meaningful and adds value. Rewards and recognition are key in employee engagement because people want to feel respected and have a sense of accomplishment. Employees want to be recognised for their achievements and when they are given this recognition, it boosts their self-esteem and gives them a sense of worth or having contributed towards the success of something. This is supported by Maslow's (1943) theory of motivation and hierarchy of needs that alludes to the fact that when the basic needs of physiology, safety and love are satisfied, the need for esteem and self-actualisation emerges. Maslow (1943) says this about esteem needs:

All people in our society (with a few pathological exceptions)
have a need or desire for a stable, firmly based, (usually) high
evaluation of themselves, for self-respect, or self-esteem, and for
the esteem of others. By firmly based self-esteem, we mean that
which is soundly based upon real capacity, achievement and
respect from others. These needs may be classified into two
subsidiary sets. These are, first, the desire for strength, for
achievement, for adequacy, for confidence in the face of the
world, and for independence and freedom. Secondly, we have
what we may call the desire for reputation or prestige (defining
it as respect or esteem from other people), recognition, attention,
importance or appreciation. (p. 381)

Rewards and recognition that are in line with achievements will be positively related to increased performance. For the participants in this study, they wanted to be rewarded with being given the opportunity to participate in the activities of the organisation.

\section{Summary}

The outcome of the literature review confirmed the findings of the research study and highlighted poor practices in both performance management and employee engagement. The major contributors to poor performance are lack of communication and engagement, employee empowerment and authentic leadership.

\section{Research methodology and design Introduction}

Although extensive literature exists for both performance management and employee engagement, this research study was aimed at gaining insights into employees' perceptions of performance management and employee engagement within a South African context and whether they perceived a relationship existed between the two.

\section{Design}

The research study employed a cross-sectional research design methodology that was exploratory in nature and was conducted with a qualitative focus. It was based on literature review of employee engagement and performance management, and considered interview data collected from 20 South African employees.

\section{Participants}

Participants comprised 20 employees in various functions within operations of a fast-moving consumer goods multinational company based in Johannesburg, Gauteng province, South Africa. Permission was sought and received from the organisation to conduct the research study and allow willing participants to participate in the research. It was made clear that there were no incentives. The organisation and participants were made aware that the results were for 
academic purposes and may be published in an academic journal. It was further explained that all information would be kept strictly confidential, with all transcripts and recordings destroyed after final submission. The company and participants would remain anonymous. All participants took part voluntarily and were afforded the opportunity to decline or terminate participation throughout the interview process. The criterion for participation was that participants had at least 1 year of working experience, was part of the performance management process, understood English and completed grade 12 .

\section{Population and sampling method}

The organisation with a workforce of approximately 450 employees at the time of the study, comprising 356 permanent employees and 94 contract workers, had been operating in South Africa for 37 years. Non-probability convenience sampling is a sampling method where not all the participants or units within the target population have an equal chance of being used in the study and members in the target population are used because they meet practical criteria (Etikan, Musa, \& Alkassim, 2016). As the study was exploratory in nature and sought to investigate the views of employees across all levels of operations within the organisation, non-probability convenience sampling was used. This was because of ease of access to employees and time constraints as employees were given permission to utilise company hours to participate in the study. The sample selection consisted of 20 employees across various functions and levels within operations of the organisation, all of whom formed part of the performance management process and were involved in employee engagement activities. The majority of participants (60\%) were males. In terms of ethnicity, 55\% were blacks, 30\% were Indians, $10 \%$ were whites and $5 \%$ were mixed-race people. All the participants were assigned codes (A1 to A20) to protect their anonymity. The levels within the organisation were categorised into shop floor personnel, office personnel, first-line management, site leadership and directorate (see Table 1).

\section{Research instrument}

According to Foddy (1993), open-ended questions allow participants to express themselves freely and say what they are thinking without being influenced by the researcher. The exploratory nature of the research study allowed the researcher to use an open-ended discussion guide to conduct semi-structured interviews with the participants. This enabled the researcher to ask the same open-ended questions to all participants while still allowing participants to expand and elaborate on their responses. It also allowed the researcher to probe for further understanding and clarity, yet remain on track to investigate the objectives of the study. The challenge of such an instrument is that it is time-consuming - both in the time taken to conduct each individual interview and in transcribing and coding of the data.
TABLE 1: Participant demographics.

\begin{tabular}{llll}
\hline Participant code & Male/ Female & $\begin{array}{l}\text { Years with } \\
\text { organisation }\end{array}$ & Level within organisation \\
\hline Group 1: Shop floor personnel & & \\
A2 & Male & $>2-<5$ & Shop floor personnel \\
A3 & Male & $>1-<2$ & Shop floor personnel \\
A4 & Male & $>2-<5$ & Shop floor personnel \\
A6 & Female & $>1-<2$ & Shop floor personnel \\
A8 & Female & $>5-<10$ & Shop floor personnel \\
A10 & Male & $>10$ & Shop floor personnel \\
A18 & Female & $>5-<10$ & Shop floor personnel \\
A19 & Male & $>5-<10$ & Shop floor personnel \\
A20 & Male & $>10$ & Shop floor personnel \\
Group 2: Office personnel & & \\
A13 & Female & $>1-<2$ & Office personnel \\
A16 & Female & $>10$ & Office personnel \\
Group 3: First-line management & & \\
A9 & Female & $>1-<2$ & First line management \\
A11 & Female & $>1-<2$ & First line management \\
A14 & Male & $>5-<10$ & First line management \\
A15 & Male & $>2-<5$ & First line management \\
Group 4: Director and site leadership & $>5-<10$ & Site leadership \\
A1 & Male & $>1-<2$ & Site leadership \\
A5 & Male & $>2-<5$ & Site leadership \\
A7 & Male & $>5-<10$ & Site leadership \\
A12 & & Director \\
A17 & &
\end{tabular}

\section{Data collection}

The data collection process included the researcher doing an online review of accredited South African and international journal articles applicable to the study to understand what the findings and views of academics about performance management and employee engagement were. Based on this knowledge, the researcher compiled an interview discussion guide to aid in gathering the relevant insights from participants on performance management and employee engagement. A semi-structured interview process was applied, which allowed for open-ended questions and a discussion to evolve, which allowed participants' views and thoughts to come through with ease. Interviews occurred during business hours at the organisation's premises at times that were suitable to the participants and did not negatively impact operations. Participants were encouraged to give honest unbiased feedback. Interviews took place on a one-toone basis in the researcher's office which is secluded, thus maintaining confidentiality. Each interview was lasted approximately between 45 and $60 \mathrm{~min}$, with participants being asked to elaborate and give examples to ensure that the interviewer understood and correctly noted the points being made. After the interviews had been concluded and if the researcher required further clarity on any of the responses from the participants, then this was done through either telephonic or face-to-face interview depending on the availability of the participants.

\section{Data analysis}

Shortly after each interview was conducted, the researcher went through the recordings and notes to establish that she understood participant responses; if clarity was required, 
then this was sought at the earliest convenience of the participant. In total, 20 interviews were conducted, after which data saturation was reached, with no new codes and themes emerging further; the researcher did an initial readthrough of the data to familiarise herself with it. Then participant responses were transcribed into a Microsoft Excel worksheet per question to facilitate analysis of the data. An important step in analysing and organising qualitative data is being able to 'see' and assign codes or tags to express or infer information gathered during the study. Codes can be assigned to phrases, words or whole paragraphs (Basit, 2003). Responses for each question were then reviewed and analysed for key words and phrases for which codes were assigned. The codes and phrases that were identified and highlighted were then collated into one data set relevant to each question. The data set was then analysed for similarities, differences and repeat themes and organised into first-order theme clusters, organising themes and emerging themes for which each theme was named. This report highlights the themes for performance management and employee engagement which emerged from the responses.

\section{Thematic analysis}

Accordings to Braun and Clarke (2006), thematic analysis has increased in popularity as a method of analysing qualitative data because of its accessibility and theoretic flexibility, as it can be used within different frameworks to answer various types of research questions. Thematic analysis is a search for patterns and themes within a data set that explores commonalities of experiences, ideas, thoughts, views and perceptions, thus addressing the research questions being investigated. The process involves familiarising oneself with the data, coding and theme development. Feredday and Muir-Cochrane (2006) defined thematic analysis as patterns that are recognised in the data from which themes develop and become categories for analysis.

Different question types require different versions of thematic analysis which is informed by different theoretical frameworks. Braun and Clarke (2006) stated thatthematic analysis can be approached in various ways, which include coding and themes that are directed by data content, coding and themes that are directed by current concepts and theories, coding and themes that mirror the obvious data content, coding and themes that support or underpin the data, reporting of an assumed reality within the data content and focus on how a certain reality is created by the data.

A theme is characterised by patterns that highlights a point or idea of importance within the data and in relation to the research question; however, a theme that occurs more frequently is not necessarily more critical. A theme is important if it highlights something that is significant to the research question (Braun \& Clarke, 2006). Within the data set, themes denote specific patterns of meaning which is either directly observable - manifest content or references - latent content. It is important to distinguish whether themes are drawn from theoretical ideas - deductive, which allows for replication, refuting or extensions of current studies - or from the raw data - inductive, drawing from the naturally occurring themes within the data itself and remaining open to emerging concepts (Joffe 2012). Inductive analysis is like grounded theory with the analysis being data driven. Braun and Clarke (2006) stated that in inductive analysis the coding of data happens without trying to fit it into either the researcher's preconceived notions or a pre-existing framework and is data driven. The deductive theory-driven approach involves analysis of data that is limited to preconceived framework.

\section{Conducting thematic analysis}

Braun and Clarke (2006) stated that it is important that as a first step the researcher is familiar with the data and any interview recordings must be written out so that it can be read. A read-through of the entire data set is required to make notes on initial thoughts and ideas after which initial codes can be generated; this can be done manually or through the use of a software program. After the initial coding is done, codes, sentences and phrases that are similar can be grouped together as first-order theme clusters. The same is then applied with the first-order theme clusters, similar codes become organising themes and the process is repeated until a theme emerges. At this stage a review of the themes is necessary to establish if all the data fit accordingly. Define and name themes so that they fit in with all the data and finally compile the report.

\section{Validity and reliability}

According to Creswell and Miller (2000), the concept of validity in qualitative research is not easy but researchers undertaking qualitative research must show that the study is credible, using a validity procedure. Creswell and Miller define validity as how credibly and accurately the participants view and ideals regarding the phenomena have been accounted for. There are several validity procedures, but for the purpose of this study, the thick, rich description to show credibility was used. The purpose of which was to give the readers a sense that they could have been in the interview and to allow the readers to 'see' the emotion coming through the words. Ponterotto (2006) defines thick description as:

[T]he researcher's task of both describing and interpreting observed social action (or behaviour) within its context. Thick description accurately describes observed social actions and assigns purpose and intentionality to these actions, by way of the researcher's understanding and clear description of the context under which the social actions took place. Thick description captures the thoughts and feelings of participants as well as the relationships among them. Thick meaning of findings leads readers to a sense of verisimilitude, wherein they can cognitively and emotively 'place' themselves within the research context. (p. 543)

According to Cypress (2017), reliability in qualitative research is about ensuring that the findings are congruent with the 
reality and the researcher does not manipulate the phenomenon of interest. Whilst the research study was conducted ethically, and the results reported as accurately as possible, it must be noted that the researcher was the source of data collection.

\section{Ethical consideration}

Ethical clearance was obtained the Ethics Committee: Wits Business School (clearance number: WBS/BA1254736/252).

\section{Results and findings Introduction}

Participant responses were reviewed, interpreted and analysed for commonalities, differences and repeat ideas. The results were categorised into first-order theme clusters, organising themes and emerging themes. The research study revealed seven common themes for performance management and employee engagement. The common themes have further been categorised into major themes based on their relevance to the study, significance in terms of participant responses and the number of times it had emerged per research question. Major themes that emerged included engagement and communication, employee empowerment and authentic leadership. Several other themes that emerged included development and improvement, performance management soundness and roles, workplace culture and reward, recognition and appreciation.

\section{Findings: Performance management}

\section{Are employees satisfied with the way they are performance managed?}

The purpose of research question 1 was to explore the level of satisfaction employees felt with which they were performance managed and to determine what worked and what could be improved.

Of the total participants, $45 \%$ were dissatisfied with the way they were performance managed, citing no discussions taking place, key performance indicators not being aligned with their roles and lack of regular interaction and feedback from direct line managers. The $30 \%$ of participants that were satisfied with the way they were performance managed said that their objectives were aligned with the business objectives and they understood them. The remaining $25 \%$ of participants who were somewhat satisfied mentioned that there is room for improvement in terms of interaction between management and lower levels; they cited a need for increased training to enhance skills and knowledge and more regular miniassessments during the year.

Group 1: Shop floor personnel. About $55 \%$ of group 1 participants were not satisfied with the way they were performance managed. Participants perceived a gap in the focus placed on the development of employees and the lack of managerial interaction.
Group 2: Office personnel. While both participants, participant A13 and A16, in group 2 were satisfied with the way they were performance managed, it was suggested that increased discussions throughout the year would improve the overall performance management process.

Group 3: First-line management. All four participants in group 3 were dissatisfied with the way in which they were performance managed. Participants were despondent because of their managers' inability to effectively manage performance and the lack of commitment by managers to engage and have meaningful discussions with employees. There was a perception that the performance management process lacked credibility and that measures focused on results only and did not consider behaviours.

Group 4: Site leadership and directorate. All participants in group 4 were satisfied with the way they were performance managed and agreed that it worked; however, they also all agreed that improvement was required as the performance management process was not always consistently applied. Changes in organisational objectives did not always translate to changes in objectives, which resulted in lack of strategic focus. While most of group 4 participants mentioned improvements in the performance management system itself, one participant was frustrated with his manager's lack of ability to justify how he rated his performance and thus perceived the performance management process as lacking objectivity.

Participants from groups 2 and 3 shared the same view that regular discussions must happen to improve performance. A leader's role is to provide supportive management to employees that could motivate them to participate and use discretionary effort.

The responses from groups 3 and 4 reinforced Gruman and Saks' (2011) theory that the quality of the leader plays a pivotal role in the success or failure of managing performance. The commonality in responses of participants across all four groups reiterated the importance of a sound and authentic leadership in managing performance effectively.

\section{How do you want to be performance managed?}

The purpose of this question was to understand which constructs of managing performance were important to participants to drive continuous improvement in performance.

Participants were all aligned on how they wanted to be performance managed; they wanted to be empowered to take decisions and come up with new ideas. It was important for them to feel included and be part of the organisation's success through coaching and mentoring. The need for regular discussions and feedback was also highlighted as significantly important. 
Group 1: Shop floor personnel. Most of the participants in this group shared similar views regarding how they wanted to be performance managed. Peer reviews, better communication between employees and management, and employee empowerment through coaching, mentoring and recognition were important.

Group 2: Office personnel. Participants in group 2 shared the same sentiment around being recognised for good work and wanted as recognition the freedom to make decisions and to feel empowered. Lockwood (2007) argued that productive employees are those who are empowered to make decisions, have access to information, are equipped with the right capabilities and have their efforts recognised and rewarded.

Group 3: First-line management. Participants in this group all shared similar views with each other and group 1 on how they wanted to be performance managed. It was important that the performance management process was credible, was used as a tool for improvement and not punishment, and boundaries within which they operated extended. Aguinis (2013) states that performance management is an ongoing continuous process that includes agreeing on set targets as aligned to the organisation's objectives that will deliver business results, reviewing performance and including a two-way feedback and coaching that ensures the employee's contribution towards the organisation's success is clear.

Group 4: Site leadership and director. Participants in group 4 wanted to be able to give input when decisions affected them and for the business to consider more than just the achievement of objectives, and also the values lived by the employee and the behaviours displayed.

It was important for participants across all the groups that performance is managed on clearly set objectives aligned to their roles.

\section{What is the common reason for the level of performance in South African companies?}

Strauss and Du Toit (2010) argued that South Africa lacks competitiveness. The purpose of the question was to understand the underlying cause of South African companies lacking competitiveness.

Participants responded that the common reasons for the level of performance in South African companies is the high skills shortage, lack of authentic leadership, lack of employee empowerment, ineffective engagement and poor communication.

Group 1: Shop floor personnel. Participants in group 1 shared similar views regarding the reasons for the current performance levels in South African companies, which were more relational: poor leadership, lack of interaction and communication between management and employees, and employees being afraid to voice their concerns. Lack of training and skills development was also mentioned as a reason for poor performance.

Group 2: Office personnel. Participants in group 2 shared different views on the reason for the current levels of performance within South African organisations. Managers' partiality and lack of employee empowerment were cited as reasons.

Group 3: First-line management. Participants in group 3 shared the same view that managers' partiality was an issue when it came to managing performance and developing employees. They were aligned in their view that employee's ambitions and development were not a priority for the organisation.

Group 4: Site leadership and director. All participants in group 4 believed the level of performance in South African organisations was poor, including theirs, citing lack of performance standards, a skills shortage and employee retention as causes for concern. Tables 2 to 4 show a summary of the findings for questions 1 to 3 relating to Performance Management.

TABLE 2: Summary of findings for question 1 - Performance management. Are employees satisfied with the way they are performance managed?

\begin{tabular}{|c|c|c|}
\hline Emerging theme & Findings & Key quotes \\
\hline $\begin{array}{l}\text { Development and } \\
\text { improvement }\end{array}$ & $\begin{array}{l}\text { Employees are frustrated with the absence of } \\
\text { discussions pertaining to career development. }\end{array}$ & $\begin{array}{l}\text { 'More training must be done for employees to enhance their skills and knowledge in terms of } \\
\text { efficiency'. (Participant A10) }\end{array}$ \\
\hline \multirow[t]{3}{*}{$\begin{array}{l}\text { Performance management } \\
\text { soundness and roles }\end{array}$} & $\begin{array}{l}\text { Performance management confused with } \\
\text { performance appraisals. }\end{array}$ & $\begin{array}{l}\text { 'I do not agree on how the rating is determined and I question the ability of the line manager to } \\
\text { justify it. As much as the performance management is to be objective, it lacks in this regard'. } \\
\text { (Participant A5) }\end{array}$ \\
\hline & \multirow[t]{2}{*}{ Poor strategic focus. } & $\begin{array}{l}\text { 'There might be changes in company strategy and objectives, but your objectives remain } \\
\text { unchanged'. (Participant A12) }\end{array}$ \\
\hline & & $\begin{array}{l}\text { 'My performance was evaluated by managers who do not interact with me, subjectively. There } \\
\text { was no discussion on why I was given the rating I achieved. I was told what rating to give to my } \\
\text { subordinate without justification'. (Participant A9) }\end{array}$ \\
\hline \multirow{2}{*}{$\begin{array}{l}\text { Engagement and } \\
\text { communication }\end{array}$} & \multirow[t]{2}{*}{ Lack of timely and meaningful feedback. } & 'Perhaps more regular mini-assessments during the year'. (Participant A13) \\
\hline & & $\begin{array}{l}\text { 'Employees need to be told how they are performing regularly to correct poor performance } \\
\text { instead of believing that they are performing at an acceptable level'. (Participant A14) }\end{array}$ \\
\hline \multirow[t]{2}{*}{ Authentic leadership } & \multirow[t]{2}{*}{$\begin{array}{l}\text { Unsupportive management. } \\
\text { Key quotes: }\end{array}$} & $\begin{array}{l}\text { 'The interactive aspect between management and employees to set out goals and achieve them } \\
\text { is lacking. Management prefers an autocratic approach to an inclusive one. More commanders } \\
\text { rather than do this way leaders'. (Participant A8) }\end{array}$ \\
\hline & & $\begin{array}{l}\text { 'The performance management process lacks personal interaction between manager and } \\
\text { employee, so I am not satisfied with the process. What would work for me, would be to sit down } \\
\text { with my line manager and discuss my career development and my manager's expectations } \\
\text { regarding my current position. For me to perform well there must be good, open communication } \\
\text { between my manager and I. I think managers should take time to know their employees as that } \\
\text { would really help in terms of performance management'. (Participant A6) }\end{array}$ \\
\hline
\end{tabular}


TABLE 3: Summary of findings for question 2 - Performance management. How do you want to be performance managed?

\begin{tabular}{|c|c|c|}
\hline Emerging theme & Findings & Key quotes \\
\hline \multirow[t]{2}{*}{$\begin{array}{l}\text { Engagement and } \\
\text { communication }\end{array}$} & Lack of timely and meaningful feedback & $\begin{array}{l}\text { 'The process should be inclusive of my input, my manager to empower me - coach and mentor me } \\
\text { and share regular feedback on my progress. I also want to be recognised for going the extra mile as } \\
\text { this will keep me motivated'. (Participant A8) }\end{array}$ \\
\hline & & $\begin{array}{l}\text { 'Performance for me is about having the right attitude, passion and a conducive environment. All } \\
\text { these start with good communication between management and employees. Management must } \\
\text { create an environment where there is open dialogue and no intimidation'. (Participant A6) }\end{array}$ \\
\hline \multirow[t]{2}{*}{ Workplace culture } & Culture of fear and intimidation. & 'More opportunity to give my input and just to be heard'. (Participant A1) \\
\hline & Employees are not given a voice. & $\begin{array}{l}\text { 'A culture free of fear where employees can be free to express opinions and suggestions to the } \\
\text { manager without feeling side-lined'. (Participant A6) }\end{array}$ \\
\hline $\begin{array}{l}\text { Rewards, recognition } \\
\text { and appreciation }\end{array}$ & Lack of appropriate recognition. & $\begin{array}{l}\text { 'I would like acknowledgement for good work. I would also want more freedom to make decisions } \\
\text { relating to the work I do as recognition of the competencies displayed'. (Participant A16) }\end{array}$ \\
\hline $\begin{array}{l}\text { Employee } \\
\text { empowerment }\end{array}$ & Limited boundaries that cause endless frustration. & $\begin{array}{l}\text { 'Clear smart objectives must be agreed on between myself and my manager at the beginning of the } \\
\text { year with adequate resources in place. I want to be given flexibility in the "how" I deliver on those } \\
\text { set objectives if it is in line with the company's values and principles. I do not appreciate to be micro- } \\
\text { managed but believe in regular feedback sessions with my manager to discuss the challenges I am } \\
\text { facing and support I need from him. I also appreciate recognition where I have performed well to } \\
\text { help boost my morale'. (Participant A11) }\end{array}$ \\
\hline
\end{tabular}

TABLE 4: Summary of findings for question 3 - Performance management. What is the common reason for the level of performance in South African companies?

\begin{tabular}{lll}
\hline Emerging theme & Findings & Key \\
\hline Development and & Employees are frustrated with the absence of \\
improvement & discussions pertaining to career development. \\
& $\begin{array}{l}\text { Inability of organisation to retain employees with the } \\
\text { right talent and competencies. }\end{array}$ & I
\end{tabular}
Key quotes

'Severe skills shortage, given the history and background together with the current economic climate, many people were not given the opportunity to gather the right level of experience. I also believe that employees require more training, guidance and coaching across all levels. Sustained performance requires a fair and objective performance process that is consistently applied. This will lead to better retention and growth for employees and organisations alike'. Employees do not have the right level of experience. $\begin{aligned} & \text { applied. This will } \\ & \text { (Participant A5) }\end{aligned}$

'There's a shortage of skills so when the correct skills have been identified, measures must be taken to retain these skills. We don't train and develop employees for sustained performance. Employees to retain these skills. We don't train and develop employees for sustained performance. Employees (Participant A7)

Engagement and communication

Communication and engagement characterised by a crisis.

Misalignment between what is communicated and what is expected.

Messages to shop floor not simple and get distorted.

\section{Employee Employees are not given a voice.}

empowerment Tight employee boundaries.

Authentic leadership Leaders lack emotional intelligence. Managers' partiality.

Workplace culture 'Us and them' mentality. Culture of fear and intimidation.

Employees lack the right attitude across all levels.
'Lack of motivation, employees are afraid of the consequences when things go wrong. Managers are secretive, we hear things from other employees. Not enough training is given to shop floor workers. Employees cannot share their opinions or issues because of victimisation, we must wait for feedback after asking several times before we are told anything'. ( Participant A4)

'The people element is lacking. Managers only talk to employees when things go wrong or if targets are not met. Managers say one thing and expect something else. They say they want safety and quality to come first but if we highlight issues, they ignore them and say produce. People lack motivation, some are scared. People are not skilled enough; all this affects the level of performance'. (Participant A8)

'Organisations do not support employees who want to apply their knowledge and experience but force them to adapt to the past ways of working even if it is not value adding, which leads to employees being demotivated'. (Participant A11)

'Employees not feeling empowered and lacking purpose as the reasons for low performance, including lack of incentives to perform well'. (Participant A16)

'High level of office politics that causes employees not to care and managers who show favouritism needs to be addressed in local companies before performance improves'. (Participant A13)

'Managers give instructions rather than talking to people and giving guidance. People are scared to make mistakes because they fear being fired. Management must increase training and coaching on the shop floor. They are never on the shop floor. People are not treated equally'. (Participant A20)

"There is an "us and them" mentality at most organisations. Communication is not always free flowing, and messages are not always clear, especially downstream. Messages are not simple enough to be understood by the shop floor and often get distorted. Employees are not given room to voice their expectations and aspirations which causes a lack of motivation. There is not much interaction between employees and management when it comes to individual ambitions. It is always about the organisation's needs and requirements and less about individual development'. (Participant A15)

\section{Findings: Employee engagement}

\section{What do you regard as 'employee engagement'?}

The purpose of this question was to gauge which constructs of employee engagement were of relevance and importance to the participants.

Employees want to know that they are adding value and contributing to the organisation's success, having a voice motivates them to get more involved and give more of themselves. Greater positive engagement and involvement will result in better performance.

Group 1: Shop floor level. Participants in group 1 shared similar understanding with each other regarding employee engagement, which involved more employee connection and emotion. Their understanding of employee engagement included employees living the values of the organisation and being empowered to have a voice.

Group 2: Office personnel. Participants in group 2 differed in their understanding of employee engagement from each other yet were aligned to group 1 with regard to employees being empowered and allowed to contribute to the organisation's success.

Group 3: First-line management. For participants in group 3, employee engagement was about communication, employee connection and emotion to drive performance.

Group 4: Site leadership and director. Participants in this group all shared different ideas with each other about employee engagement. Some participants alluded this to management 
taking the lead, while the rest of the participants said it was the employees who took the lead and made the effort.

\section{What can management do to increase and improve employee engagement?}

The purpose of this question was to understand the current underlying issues that organisations are facing in terms of employee engagement and get the participants' views on how it can be improved upon.

Participants highlighted that to improve employee engagement, discussions and feedback must be regular and not a once- or twice-a-year exercise. Engagement and communication need to improve, and employees must be given a voice. Development of employees must be a key focus and employees need to be rewarded, appreciated and recognised for their contribution to the organisation's success. Leaders need to be more approachable, supportive and willing to create an environment of trust and respect.

Group 1: Shop floor personnel. Participants in this group shared common views on how to improve employee engagement, with the focus being on improving communication and developing employees through training. A key construct was the lack of leadership, which was further supported by group 3 in their responses.

Group 2: Office personnel. Participants in this group shared similar ideas on giving employees a platform to have a voice.

Group 3: First-line management. Participants in this group all shared the same view that leadership was lacking; and from their emotion it was clear that this was a serious issue that was negatively impacting performance.

Group 4: Site leadership and director. All the participants in this group had different ideas on how to increase and improve employee engagement levels; for some participants, the focus was on empowering employees through involvement and development, and for others it was more about addressing issues and concerns that impact employee engagement.
Does a relationship exist between employee engagement and performance management?

The purpose of this question was to understand if participants perceived a relationship existed between employee engagement and performance management.

All participants in all four groups agreed that there was a relationship between employee engagement and performance management.

Group 1: Shop floor personnel. Participants in this group made it clear that increased communication regarding performance was a priority; they wanted to have meaningful discussions. They also wanted to have a voice.

Group 2: Office personnel. Participants in this group alluded to the fact that employees need empowerment to achieve increased performance.

Group 3: First line management. Group 3 participants spoke of behavioural factors and alluded to cognitive engagement as the factor to increase performance.

Group 4: Site leadership and director. Participants were aligned in their view that increased engagement will encourage employees to take initiative and go the extra mile.

\section{Discussion on the research findings}

The research findings will be discussed in relation to the research objectives and questions based on the literature review of specific constructs within performance management and employee engagement. The use of the qualitative research method was to gain insights into the experiences of employees with regard to performance management and employee engagement. It was important to understand how the participants perceived performance management, what they thought was key to ensuring greater employee engagement and if they perceived a link between the two. Tables 5 to 7 show the summary findings to question 1 to 3 as it relates to employee engagement.

TABLE 5: Summary of findings for question 1 - Employee engagement. What do you regard as 'employee engagement'?

\begin{tabular}{|c|c|c|}
\hline Emerging theme & Findings & Key quotes \\
\hline \multirow[t]{3}{*}{$\begin{array}{l}\text { Engagement and } \\
\text { communication }\end{array}$} & $\begin{array}{l}\text { Management openly engages with employees } \\
\text { through a two-way effective communication. }\end{array}$ & $\begin{array}{l}\text { 'It's about getting down onto the shop floor and interacting with the employees and understanding } \\
\text { what challenges they are facing but also appreciating the work that they are doing'. (Participant A1) }\end{array}$ \\
\hline & \multirow[t]{2}{*}{ Organisation interacting with employees. } & $\begin{array}{l}\text { 'Employee engagement is where the employee feels part of the business. The morale is high at all } \\
\text { levels. There is a sense of trust and communication is filtered to all levels. Employees make } \\
\text { improvements without being told'. (Participant A7) }\end{array}$ \\
\hline & & $\begin{array}{l}\text { 'Consultation of employees that affect their workplace conditions and workplace relations'. } \\
\text { (Participant A17) }\end{array}$ \\
\hline \multirow[t]{2}{*}{ Workplace culture } & $\begin{array}{l}\text { Employees live the organisation's values, and they are } \\
\text { proud of their organisation. }\end{array}$ & \multirow{2}{*}{$\begin{array}{l}\text { 'Employee engagement is a concept in which the employee understands and lives the values of the } \\
\text { organisation. The employee has the drive to see the organisation thriving and therefore does what it } \\
\text { takes to meet and exceed the expectation of the targets set for him. It is also important for the } \\
\text { employee to have his voice heard and be part of the decision-making so that he feels included and } \\
\text { that his input matters'. (Participant A6) }\end{array}$} \\
\hline & Employees show dedication, care and enthusiasm. & \\
\hline \multirow{4}{*}{$\begin{array}{l}\text { Employee } \\
\text { empowerment }\end{array}$} & Employees have a voice. & \multirow{2}{*}{$\begin{array}{l}\text { 'It is also important for the employee to have his [or her] voice heard and be part of the decision- } \\
\text { making so that he [or she] feels included and that his [or her] input matters'. (Participant A6) }\end{array}$} \\
\hline & $\begin{array}{l}\text { Employees take accountability and are results } \\
\text { focused. }\end{array}$ & \\
\hline & Employees use discretionary effort and find solutions. & $\begin{array}{l}\text { 'Opportunity for employees to participate and contribute to the direction an organisation takes'. } \\
\text { (Participant A16) }\end{array}$ \\
\hline & $\begin{array}{l}\text { Employees' boundaries within which they operate are } \\
\text { extended. }\end{array}$ & $\begin{array}{l}\text { 'Employee engagement is the connection and feelings employees have towards their organisation } \\
\text { and the effort they are willing to put in to ensure its success. Employees that are engaged are happy } \\
\text { to come to work, they want to deliver results, they are accountable, enthusiastic, dedicated and they } \\
\text { use discretionary effort. They believe in their company and will defend it because they are proud of } \\
\text { it. They find solutions and get involved'. (Participant A9) }\end{array}$ \\
\hline
\end{tabular}


TABLE 6: Summary of findings for question 2-Employee engagement. What can management do to increase and improve employee engagement?

\begin{tabular}{|c|c|c|}
\hline Emerging theme & Findings & Key quotes \\
\hline $\begin{array}{l}\text { Development and } \\
\text { improvement }\end{array}$ & Introduce effective training programmes. & $\begin{array}{l}\text { 'Talented employee should be identified and encouraged to excel more, whereas employees lacking } \\
\text { experience or competence should be guided and trained to better their skills and increase } \\
\text { performance.' (Participant A8) }\end{array}$ \\
\hline $\begin{array}{l}\text { Rewards, recognition and } \\
\text { appreciation }\end{array}$ & Recognise achievements and talents. & $\begin{array}{l}\text { 'Managers need to give employees recognition. Management should be role models for employees. } \\
\text { There needs to be one-on-one communication to understand employee issues. Feedback is important } \\
\text { on issues that are raised. All issues or concerns will not always have the desired outcome, but } \\
\text { employees appreciate the fact that their concerns were acknowledged and investigated. Training and } \\
\text { development in their roles. Personal growth is a key factor'. (Participant A7) }\end{array}$ \\
\hline Authentic leadership & Lack of supportive management. & $\begin{array}{l}\text { 'Management can show fairness in the workplace and not be subjective when managing performance } \\
\text { Show appreciation for achievements met. Management should learn email etiquette and not send } \\
\text { emails that are rude as this intimidates people and results in people not engaging. Management must } \\
\text { walk the talk. They should not say one thing and do another. Management should be transparent; } \\
\text { currently there is no trust between management and employees and there is an "us" versus "them" } \\
\text { mentality in the organisation. If there is no trust, employee engagement will be poor. Management } \\
\text { should be visible and accessible to employees without them feeling afraid. Genuine relationships } \\
\text { between employees and their supervisors and management inspire trust and commitment'. } \\
\text { (Participant A9) }\end{array}$ \\
\hline $\begin{array}{l}\text { Engagement and } \\
\text { communication }\end{array}$ & Greater engagement required. & $\begin{array}{l}\text { 'Create working environments that are conducive for two-way communication. Management cannot } \\
\text { expect to engage employees if they are not willing to listen to what the employees have to say. } \\
\text { Management should not wait until there is a crisis before they engage employees it should be a } \\
\text { regular thing. It must be built into the culture of an organisation that communication and employee } \\
\text { engagement is a norm rather than an occasional event that characterises a crisis'. }\end{array}$ \\
\hline Employee empowerment & Enable employees to have a voice. & $\begin{array}{l}\text { 'I think the introduction of an employee forum for raising concerns or for inviting staff input would be } \\
\text { beneficial'. (Participant A16) }\end{array}$ \\
\hline Workplace culture & $\begin{array}{l}\text { Create a culture of trust. } \\
\text { Create a conducive working environment. } \\
\text { Communication and employee engagement } \\
\text { must be built into the culture of the } \\
\text { organisation. }\end{array}$ & $\begin{array}{l}\text { 'Creating an environment of open dialogue and less blame will be a good start. It is important that } \\
\text { employees can talk to her manager about what makes them demotivated. Team-building exercises } \\
\text { and one-on-one sessions between the employee and management can improve employee } \\
\text { engagement. Most employees view senior leaders as people who want to punish them when things } \\
\text { go wrong, so the culture needs to change'. (Participant A6) }\end{array}$ \\
\hline
\end{tabular}

TABLE 7: Summary of findings for question 3 - Employee engagement. Does a relationship exist between employee engagement and performance management?

\begin{tabular}{ll}
\hline Emerging theme & Findings \\
\hline Employee empowerment & $\begin{array}{l}\text { Employees are given a voice. } \\
\text { Empowered employees are productive. }\end{array}$ \\
$\begin{array}{l}\text { Engagement and } \\
\text { communication }\end{array}$ & $\begin{array}{l}\text { Constructive and honest feedback encourages } \\
\text { improvement in performance. } \\
\text { Meaningful discussions allow for sharing of } \\
\text { thoughts and ideas. } \\
\text { Regular communication allows for quicker } \\
\text { resolution of issues. }\end{array}$ \\
\hline
\end{tabular}

'Yes there is. The more employee engagement occurs, the more feedback is provided to the
employee and all concerns can be addressed timeously, the engagement sessions can also clear up

Key quotes

way an employee can feel valued is if there is [a] high level of engagement between them and the way an employee can feel value
employer'. (Participant A11)

'Yes. An employee who feels empowered through participation is more motivated and therefore would put in greater effort to achieve or exceed targets'. (Participant A16)

'There is a link between employee engagement and performance management, because constant communication from management allows me to understand expectations and deliver on them. Regular discussions on performance help me to improve provided that the comments are constructive and honest. This open communication allows for support to be provided by my manager and for feedback to be given and received by us both (Participant A3). employee and all concerns can be addressed timeously, the engagement sessions can also clear up want to help him grow'. (Participant A14)

'Yes. It is not possible to effectively manage performance if you are not regularly engaging with employees. Regular discussions and feedback would result in the employee feeling valued which would motivate him to perform better. Engaged employees who feel valued are more productive'. (Participant A15)

\section{Objective 1: Understand how to effectively engage employees to ensure increased performance}

\section{South African employees perceive the following as key constructs to improve performance}

Engagement and communication: It was important for employees to have clear discussions regarding objectives to deliver against expectations, and it was also of equal importance to have regular discussions and feedback about their performance. A major gap identified in the research study was the lack of regular and honest performance discussions, including timely and meaningful feedback. Participants explained that regular discussions and timely feedback would help them address gaps within their own performance to achieve key performance indicators, which would positively impact the organisation's performance. This finding was supported by Aguinis (2013), who asserted that timely and meaningful feedback allows for employees to be supported in correcting performance to achieve individual and business objectives.
Authentic leadership: The data collected from the research study revealed a gap in leadership, with participants highlighting managers' partiality, an autocratic leadership style and managers lacking emotional intelligence as key inhibiters to performance management. This provided enough evidence to support the theory that the lack of quality leaders negatively impacts performance management. The success and effectiveness of performance management lies in the quality of the leader and his or her commitment to engage with, provide support to, challenge, coach, give constructive feedback and include his or her employees in activities of the business (Gruman \& Saks, 2011).

Employee empowerment: Empowerment is the result of increased participation of employees. Research data provided enough evidence that suggested that participants operated within tight boundaries across all levels within the organisation and were not included in decisions that affected them. There was also a perception that if they shared their ideas and views, then they will be victimised. Menon (2001) argued that allowing employees to make work-related 
decisions to enhance performance is not new in management literature and that empowering employees would allow them the ability to significantly affect organisational outcomes.

Performance management soundness and roles: Employee's perception of the performance management system is poor and often perceived as the 'big stick' (Bourne et al., 2002). Repeat findings within the research data showed that participants across all levels within the organisation perceived that the performance management process lacked credibility, performance appraisals were confused with performance management and there was poor strategic focus, with changes in organisational objectives not translating into changes in individual objectives. There was also a perception that inconsistencies existed in the way employees were performance managed - often the process being used to punish rather than to improve performance. This caused frustration and distrust, which was evident from the emotions expressed by the participants.

Development and improvement: Research study data revealed that the absence of discussions pertaining to career development, lack of training and inability of the organisation to retain employees with the right talent and competencies caused frustration amongst the lower levels. Anitha (2014) suggested that employees gain confidence when they are trained and developed, which allows them to engage significantly in their jobs. There was a perception that training only occurred if it benefited the organisation. According to Lockwood (2007), as organisations compete globally, attracting and retaining the right talent will be increasingly more important. The theories alluded to by Anitha (2014) and Lockwood (2007) asserted the importance of developing employees to enable them to perform better in their roles and retaining those employees for sustained performance.

Workplace culture: Participants perceived a workplace culture of fear and intimidation where employees were not given a voice. According to Lockwood (2007):

Research shows that organisations that provide a workplace culture with the psychological conditions of meaningfulness (job enrichment, work-role fit), safety (supportive manager and coworkers) and availability (resources available) are more likely to have engaged employees. (p. 5)

The research data supported this theory of Lockwood (2007) who argued that engaged employees are those who find themselves in a safe environment where they can share ideas and make decisions without fear.

Rewards, recognition and appreciation: It was important to note that participants within the study wanted as part of recognition for good work and displayed capabilities to be rewarded with greater decision-making opportunities. Saks and Rotman (2006) concluded that employees will positively involve and engage themselves more in their roles should they perceive that the rewards will be greater, and should they be given recognition that their work is meaningful and adds value. Appropriate rewards and recognition are key in performance management because people want to feel respected and have a sense of accomplishment.

\section{South African employees perceive the following as key constructs of employee engagement that will positively impact performance management}

\section{Engagement and communication}

Hoole and Bonnema (2015) correctly argued that engaged employees have the ability to enhance the competitiveness of organisations in the current economic landscape and that while high levels of engagement add value, low levels of engagement can have a damaging effect on the bottom line. Robertson-Smith and Markwick (2009) pointed out that various studies have demonstrated a correlation between high employee engagement levels and productivity of employees, teams and organisations. They argued that engaged employees show commitment, advocate on behalf of the organisation, show dedication, use discretionary effort and utilise their skills and abilities to support in the achievement of the organisation's goals. The research data showed significant evidence that employees want to be kept informed; they want to know what transpires within the organisation and they want to be actively involved in the decisions that affect them. The research data revealed a clear gap in the way communication occurs, often characterised by a crisis and not simple enough to be understood at all levels of the organisation. Participants asserted the need for management to openly engage employees, for two-way effective communication to take place and for the organisation to interact with employees. It was important for participants that communication and engagement is effective to help them understand how their involvement and delivering against objectives contributed to the success of the organisation

\section{Employee empowerment}

Participants within the research study asserted the need to be given a voice and for the boundaries within which they operate to be extended. It was important to them that they were given the opportunity to share ideas, be part of the decision-making process and allowed a platform to express their views which they believed would positively impact performance. This was supported by Lockwood (2007), who correctly argued that:

[W] hen employees have the power to make decisions related to their performance, can access information about company costs and revenues, and have the necessary knowledge, training and development to do their jobs - and are rewarded for their efforts - they are more productive. (p. 3)

\section{Authentic leadership}

George et al. (2007) argued that:

[A]uthentic leaders demonstrate a passion for their purpose, practise their values consistently, and lead with their hearts as well as their heads. They establish long-term meaningful 
relationships and have the self-discipline to get results. They know who they are. (p. 129)

It was important for participants within the research study that managers lead by example and connect with them. They believed that a leader who provides supportive management will motivate the use of discretionary effort and will encourage employees to go the extra mile.

\section{Rewards, recognition and appreciation}

Aguinis (2013) argued that employees are encouraged and motivated when they are recognised for good work, and that it boosts their morale. Employees who are motivated get involved and take initiative. Intrinsic motivation which is fuelled by feelings is perceived as more important to employees than monetary rewards. This theory is supported by the participants' need for their achievements and talents to be recognised.

\section{Objective 2: Ascertain how to leverage employee engagement to reboot performance management}

The purpose of this study was to understand the relationship between performance management and employee engagement within the South African context and to explore if increased employee engagement will positively impact performance management. There is substantial evidence from the research study data to support that a relationship exists between performance management and employee engagement and that an increase in the level of employee engagement will positively impact performance management. The study data were further supported by the management theories identified and the key common constructs to both employee engagement and performance management. The following major constructs will be discussed to understand how to leverage employee engagement to reboot performance management.

\section{Engagement and communication}

Lockwood (2007) argued that continuous communication is a key management tool that gives credibility to the organisation's leadership and ensures organisational success. This theme encapsulates the participants' need for increased employee engagement, personal interaction and two-way open communication. Although communication takes place, there is evidently a gap in terms of what is being communicated and what the expectations are.

Aguinis (2013) stated that through regular and continuous communication departmental and organisational goals can be made clear so that the employee could understand the connection between what he or she does and the organisation's success. Participants explained that the communication messages were not always clear or easily understood at the lower levels of the organisation. It was explained that often the messages get distorted or do not filter down to shop floor level. Changes within organisational goals and objectives are not always communicated timely and the participants felt that this hindered them from fully supporting the changes, which resulted in unachieved key performance indicators.

Aguinis (2013) argued that managers who get to know their employees foster better relationships, open the channels for an honest two-way communication and allow for them to understand how to effectively manage the employees for sustained performance. Participants explained that the interaction between direct line manager and employees was lacking and that an increase in interaction would allow for the manager to get to know his or her employees better. This increased interaction would also facilitate and encourage open, honest discussions regarding capability building and would ensure that a gap in performance is corrected quickly. It was clear that participants understood the need and importance of regular discussions to give and receive feedback on key performance indicators, to share challenges currently being experienced and to request for support to achieve individual and organisational goals and improve performance.

Aguinis (2013) argued that when employees are given a voice, they are allowed to share their ideas for improvement and raise concerns for timely resolution, which improves organisational performance. Participants wanted management to consult them on issues that affected them, and they wanted to be actively involved in the direction of the organisation. They wanted to be listened to and given a platform to voice their concerns without fear of reprimand or intimidation or a forum to share their ideas.

\section{Employee empowerment}

Menon (2001) argued that allowing employees to make work-related decisions to enhance performance is not new in management literature and that empowering employees would allow them the ability to significantly affect organisational outcomes. Empowerment is the result of increased participation of employees. This theme highlights the need for employees to be empowered to take ownership of their areas of responsibility so that managers will be able to assume a more leadership role. Participants expressed their eagerness to contribute to the success of the organisation, bring new ideas and improve the current ways of working. They were of the view that organisations must empower employees by allowing them the freedom to make decisions with regard to their areas of work if it was aligned to the values of the organisation and to express themselves freely. Participants were adamant that they do not want to be micromanaged. Several participants argued that they were hired for their skills and knowledge and should be given an opportunity to use them. They wanted the organisation to understand that every employee brings something new and different to the table and this should be encouraged and nurtured to take the organisation forward.

Employees are more interested and engaged when they know that their contribution adds value and makes a positive 
difference to the organisation (Anitha, 2014). Participants want to feel valued and feel like they are a bigger part of the organisation. It was mentioned that a higher level of engagement would make employees feel happy and valued, which would result in them performing to the maximum. It was clear that participants wanted to get involved in the core activities of the organisation but wanted management to trust that they will do their best and give off their best always.

\section{Authentic leadership}

George et al. (2007) argued that:

$[A] c$ for their purpose, practise their values consistently, and lead with their hearts as well as their heads. They establish longterm meaningful relationships and have the self-discipline to get results. They know who they are. (p. 129)

This theme points out the importance of sound and authentic leadership for performance management to be effective. The responses from the participants reinforced Gruman and Saks's (2011) theory that the quality of the leader plays a pivotal role in the success or failure of performance management. The lack of knowledge and skills of managers to effectively performance manage employees, the lack of commitment to engage and having meaningful discussions with employees, and managers' partiality were three reoccurring reasons why participants at the lower level of the organisation placed so little value on the performance management process.

Sanger (2008) argued that effective performance management requires a change in culture and skilled leaders who are willing and committed to provide considerable managerial investment. The study revealed that participants perceived their managers as being disengaged and managing from afar and with fear, giving instructions rather than leading by example. Several participants also alluded to the fact that employees were often afraid to raise concerns or give input for fear of being reprimanded or sidelined. This kind of management is unsupportive and hinders employees from achieving their full potential.

Gruman and Saks (2011) argued that leaders motivate and encourage employees to try new things by showing support, giving employees stretch roles and allowing employees to participate in discussions and get involved in decisionmaking without fear of negative consequences. A reoccurring view shared by many of the participants was that managers led by fear and intimidation, which resulted in employees being afraid to make mistakes or to speak up because they might be victimised or lose their jobs. Employees not only feared management, they resent them and lack confidence in their abilities to manage effectively. Employees are disengaged and lack motivation because of this.

Another concern shared by participants was managers' partiality and it was explained that if an employee wanted to be developed or to progress in his or her career, then he or she must ensure that he or she has the right stakeholder backing or the right network because 'selective nurturing' occurred within the organisation. Favouritism and 'friendships' often got mixed up as strong performance. This has caused lack of confidence in the performance management system and employees to become despondent. Managers lack emotional intelligence and want to ensure that the hierarchical system remains firmly in place; they will not allow communication or interaction between their subordinates and executive or global leaders and this causes tension amongst the lower levels.

\section{Implications and recommendations}

Based on the findings of this research study, the following recommendations have been made.

\section{Organisations}

Organisations must understand and acknowledge employee development and career aspirations to implement effective training and development solutions to satisfy employee needs.

The study identified that employees perceive a skills gap, and this requires that organisations partner with schools and universities to improve and attain the skills they need.

The true benefit of empowerment will only be realised if employees experience empowerment.

The study revealed that communication is not simple and therefore engagement and communication strategies cannot be 'cascaded' or 'rolled out'; they must be adapted to the location of the organisation and be cognisant of the target audience.

The levels of engagement determine the extent of individual, team and organisational success. Engagement strategies must not be a 'one-cap-fits-all' approach.

Supportive management and the quality of the leader are critical if organisations want to have a competitive advantage. It is important that organisations hire the right leaders and equip leaders with the necessary skills and capabilities to lead.

A workplace culture that is built on a foundation of inclusiveness, mutual trust and respect is required if the organisation wants to gain competitive advantage.

\section{Leaders}

Leaders must understand their true self to lead effectively, understanding the impact of their actions and behaviours when managing employee performance. Improving their levels of emotional intelligence to ensure a balanced work environment is challenging and at the same time rewarding.

Leaders need to understand the relationship between employee engagement and performance management and 
create an environment where employees have a role model, are given direction and are allowed a voice.

\section{Limitations of the study}

There are limitations of the study that must be recognised. This research was performed on a small sample size in one province in South Africa. This makes it difficult to generalise the findings to the larger South African population as the culture, values and strategic objectives are not the same across organisations. Whilst interviews were conducted across all levels of the organisations, a cross-sectional snapshot view of the current situation was taken. It did not consider what had transpired before whether the organisation was in a crisis or transition process, which could have influenced employee responses or what will happen after the snapshot has been taken.

\section{Conclusion}

The study results showed that a relationship exists between performance management and employee engagement and an increase in the level of employee engagement would result in an increase in performance. Employees were not satisfied with the way in which they were performance managed and a greater level of employee engagement is required. Employees are the greatest assets of any organisation and employers need to ensure that they create an environment of inclusiveness, engagement and trust to improve performance. People want to feel valued and want to know they add value to the organisation; therefore, managing performance should not be a tick box bi-annual exercise but a continuous process of learning, feedback, action and engagement that is embedded in the company culture. It is imperative that organisations operating within South Africa actively seek initiatives that will meet employee expectations in terms of managing performance and employee engagement.

\section{Acknowledgements Competing interests}

The authors declare that they have no financial or personal relationship(s) which may have inappropriately influenced them in writing this article.

\section{Authors' contributions}

M.G. conducted the research and M.H.R.B. supervised the research and co-wrote the article.

\section{Funding Information}

This research received no specific grant from any funding agency in the public, commercial or not-for-profit sectors.

\section{Data availability statement}

Data sharing is not applicable to this article as no new data were created or analysed in this study.

\section{Disclaimer}

The views expressed in this article are the author's own and not an official position of the institution.

\section{References}

Aguinis, H. (2013). Performance management (3rd edn.). Upper Saddle River, NJ: Pearson Education.

Aguinis, H., Gottfredson, R.K., \& Joo, H. (2012). Delivering effective performance feedback: The strengths-based approach. Business Horizons, 55, 105-111. https:// doi.org/10.1016/j.bushor.2011.10.004

Anitha, J. (2014). Determinants of employee engagement and their impact on employee performance. International Journal of Productivity and Performance Management, 63(3), 308-323. https://doi.org/10.1108/IJPPM-01-2013-0008

Basit, T.N. (2003). Manual or electronic? The role of coding in qualitative data analysis. Educational Research, 45(2), 145-154. https://doi.org/10.1080/00131880320 00133548

Baumruk, R. (2006). Why managers are crucial to increasing engagement: Identifying steps managers can take to engage their workforce. Strategic HR Review, 5(2), 24-27. https://doi.org/10.1108/14754390680000863

Bedarkar, M., \& Pandita, D. (2014). A study on the drivers of employee engagement impacting employee performance. Procedia - Social and Behavioral Sciences, 106-115. https://doi.org/10.1016/j.sbspro.2014.04.174

Bourne, M., Neely, A., Platts, K., \& Mills, J. (2002). The success and failure of performance measurement initiatives. International Journal of Operations and Production, 1288-1310. https://doi.org/10.1108/01443570210450329

Braun, V., \& Clarke, V. (2006). Using thematic analysis in psychology. Qualitative Research in Psychology, 3(2), 77-101. https://doi.org/10.1191/147808870 6qp063oa

Creswell, J.W., \& Miller, D.L. (2000). Determining validity in qualitative inquiry. Theory into Practice, 39(3), 124-130. https://doi.org/10.1207/s15430421tip3903_2

Cypress, B.S. (2017). Rigor or reliability and validity in qualitative research: Perspectives, strategies, reconceptualisation, and recommendations. Dimensions of Critical Care Nursing, 36(4), 253-256. https://doi.org/10.1097/DCC.00000 00000000253

De Leeuw, S., \& Van Den Berg, J.P. (2011). Improving operational performance by influencing shopfloor behavior via performance management practices. Journal of Operations Management, 224-235. https://doi.org/10.1016/j.jom.2010.12.009

DeNisi, A.S., \& Pritchard, R.D. (2006). Performance appraisal, performance management and improving individual performance: A motivational framework. Management and Organizational Review, 2(2), 253-277. https://doi.org/10.1111/ j.1740-8784.2006.00042.x

Etikan, I., Musa, A.S., \& Alkassim, R.S. (2016). Comparison of convenience sampling and purposive sampling. American Journal of Theoretical and Applied Statistics, 5(1), 1-4. https://doi.org/10.11648/j.ajtas.20160501.11

Feredday, J., \& Muir-Cochrane, E. (2006). Demonstrating rigor using thematic analysis: A hybrid approach of inductive and deductive coding and theme development. International Journal of Qualitative Methods, 5(1), 80-92. https://doi.org/ 10.1177/160940690600500107

Foddy, W. (1993). Constructing questions for interviews and questionnaires: Theory and practise in social research. Cambridge: Cambridge University Press.

George, B., Sims, P., Mclean, A.N., \& Mayer, D. (2007). Discovering your authentic leadership. Harvard Business Review, 2(85), 129-138.

Gopal, A. (2006, May 11). Worker disengagement continues to cost Singapore Retrieved from https://news.gallup.com/businessjournal/2

Gruman, J.A., \& Saks, A.M. (2011). Performance management and employee engagement. Journal of Human Resource Management Review, 21(2),123-136. https://doi.org/10.1016/j.hrmr.2010.09.004

Hattingh, C., De Waal, A., \& Parsons, P. (2018). Assessing high performance: A South African case study. South African Journal of Business Management, 1-8. https:// doi.org/10.4102/sajbm.v49i1.3

Hill, C.W. (2013). International business competing in the global marketplace. New York, NY: McGraw-Hill.

Hoole, C., \& Bonnema, J. (2015). Work engagement and meaningful work across generational cohorts. South African Journal of Human Resource Management, 1-11. https://doi.org/10.4102/sajhrm.v13i1.681

Joffe, H. (2012). Thematic analysis. Qualitative research methods in mental health and psychotherapy. A Guide for Students and Practitioners, 1, 210-223. https://doi. org/10.1002/9781119973249.ch15

Kahn, W.A. (1990). Psychological conditions of personal engagement and disengagement at work. Academy of Management Journal, 692-724. https://doi. org $/ 10.5465 / 256287$

Lockwood, N.R. (2007). Leveraging employee engagement for competitive advantage: HR's strategic role. Society for Human Resource Management Research Quarterly, 1(1), 1-12.

Lowry, G. (2016). Employee engagement: Communicating clear expectations. Seminars in Orthodontics, 2(2), 103-106. https://doi.org/10.1053/j.sodo.2016 04.010

Maslow, A.H. (1943). A theory of human motivation. Psychological Review, 370-396. https://doi.org/10.1037/h0054346 
Melnyk, S.A., Bititci, U., Platts, K., Tobias, J., \& Andersen, B. (2013). Is performance measurement and management fit for the future. Journal of Management measurement and management fit for the future. Journal of Management
Accounting Research Elsevier, 173-186. https://doi.org/10.1016/j.mar.2013.07.007

Menon, S. (2001). Employee empowerment: An integrative psychological approach. Applied Psychology, 50(1), 153-180. https://doi.org/10.1111/1464-0597.00052

Morrison, E.W. (2014). Employee voice and silence. The Annual Review of Organisational Psychology and Organisational Behavior, 1, 173-197. https://doi. org/10.1146/annurev-orgpsych-031413-091328

Ponterotto, J.G. (2006). Brief note on the origins, evolution, and meaning of the qualitative research concept thick description. The Qualitative Report, 11(3), 538-549.

Robertson-Smith, G., \& Markwick, C. (2009). Employee engagement: A review of current thinking. Institute for Employment Studies, 1-71.

Robinson, D., Perryman, S., \& Hayday, S. (2004). The drivers of employee engagement (pp. 1-87). Brighton: Institute for Employment Studies.

Saks, A.M., \& Rotman, J.L. (2006). Antecedents and consequences of employee engagement. Journal of Managerial Psychology, 21(7), 600-619. https://doi. org/10.1108/02683940610690169
Sanger, M.B. (2008). From measurement to management: Breaking through the barriers to state and local performance. Journal of Public Administration Review, 70-85. https://doi.org/10.1111/j.1540-6210.2008.00980.x

Schaufeli, W.B. (2013). What is engagement? In C. Truss, K. Alfes, R. Delbridge, A Schantz, \& E. Soan (Eds.), Employment engagement in theory and practice. London: Routledge.

Schaufeli, W.B., Salanova, M., Gonzalez-Roma, V., \& Bakker, A.B. (2002). The measurement of engagement and burnout: A two sample confirmatory factor analytical approach. Journal of Happiness Studies, 71-92. https://doi.org/ 10.1023/A:1015630930326

Smither, J.W., \& London, M. (2009). Performance management: Putting research into action. San Francisco, CA: John Wiley \& Sons.

Strauss, A.C., \& Du Toit, A. (2010). Competitive intelligence skills needed to enhance South Africa's competitiveness. Aslib Proceedings: New Information Perspectives, 302-320. https://doi.org/10.1108/00012531011046925

Van der Walt, F. (2018). Workplace spirituality, work engagement and thriving at work. South African Journal of Industrial Psychology, 1-10. https://doi.org/10.4102/ sajip.v44i0.1457 